American Journal of Economics and Business Administration 3 (3): 479-489, 2011

ISSN 1945-5488

(C) 2011 Science Publications

\title{
The New Reality of Competing: Strategic Marketing Intelligence and the Assessment of the Business Transformational Model Proposition
}

\author{
Nurhan Papatya and Gurcan Papatya \\ Department of Business Administration, \\ University of Suleyman Demirel, \\ Faculty of Economics and Administrative Sciences, Isparta, Turkey
}

\begin{abstract}
Problem statement: The study contains "Strategic Marketing Intelligence (SMI)" contents and formation which are directed to the business's permanent and continuous priority and the investigation of "transformational model proposition", designing bases, the thought of transformation to core competence and proposed model's applicability and advantages. Approach: This study is handled as a qualitative assessment related to restricting content of the concepts and to theorize an explanatory hypothesis under the base of data and document analysis. Now therefore, it's evaluated as a conceptual study connected to theorizing model. Results: SMI transformational model proposition has been assessed related to settling the telescoping system which is connected to the new reality of competition and integrated system leadership and helpful at determining their own system development and at easing the obtainment of the system leadership by presenting a reliable topographic map. Conclusion: A business's existing in today/future, not being a follower but to be the followed one, always without losing setting sail in a free soul, handling integral system leadership are all depend on creating permanent values/being in action oriented activities. Creating permanent values/being in action oriented activities can be possible just with correct assessed/lead informatics, inclusive/completive SMI, which is reachable, correct, full in time, cross coordinative, shared.
\end{abstract}

Key words: Competitive intelligence, Strategic Marketing Intelligence (SMI), sustaining competitive advantage, resource-based view, balanced scorecard, business transformational model

\section{INTRODUCTION}

Undoubtedly today Intercompany Competition is experienced as far more intense and higher-up than has ever been. Businesses are now no longer struggling for the superiority of product/service, but for "integrated system leadership".

In intercompany competition, the changes of play fields, the geometrical increase rate of momentum and risk cause direct increase in strategic choices of the businesses and it sets forth that the new reality of the competition, the future of the businesses will only be organized by "Strategic Marketing Intelligence" (SMI).

Under these circumstances, we come across the necessities of comprehensive thinking, over the development the business and the new cooperation/competition relations and "the transformational model". Transformational Model presents a reliable topographic map which helps to position the businesses in telescoping system, in determining the development phase of their own systems and to handle the leadership of the system (Fig. 1).
This study is handled as a qualitative assessment related to reassessing content of the concepts and to theorize an explanatory hypothesis under the base of data and document analysis. Now therefore, it's evaluated as a conceptual study connected to theorizing model. Clearly the study contains "strategic marketing intelligence" contents and formation which are directed to the business's permanent and continuous priority and the investigation of "transformational model proposition", designing bases, the thought of transformation to core competence and proposed model's applicability and advantages.

Competition and Strategic Marketing Intelligence: In today's business world, variation momentum rate is so high and it affects businesses to produce different and advantageous ideas. In other words, it is obligatory for the businesses to reassess and revise their structures and processes to envisage their future and to create novel things in new competition realities or in competitive fields.

Corresponding Author: Nurhan Papatya, Department of Business Administration, University of Suleyman Demirel, Faculty of Economics and Administrative Sciences, Isparta, Turkey

Tel: +90 024621130 45- Fax: +9002462113044 
Am. J. of Economics and Business Administration 3 (3): 479-489 2011

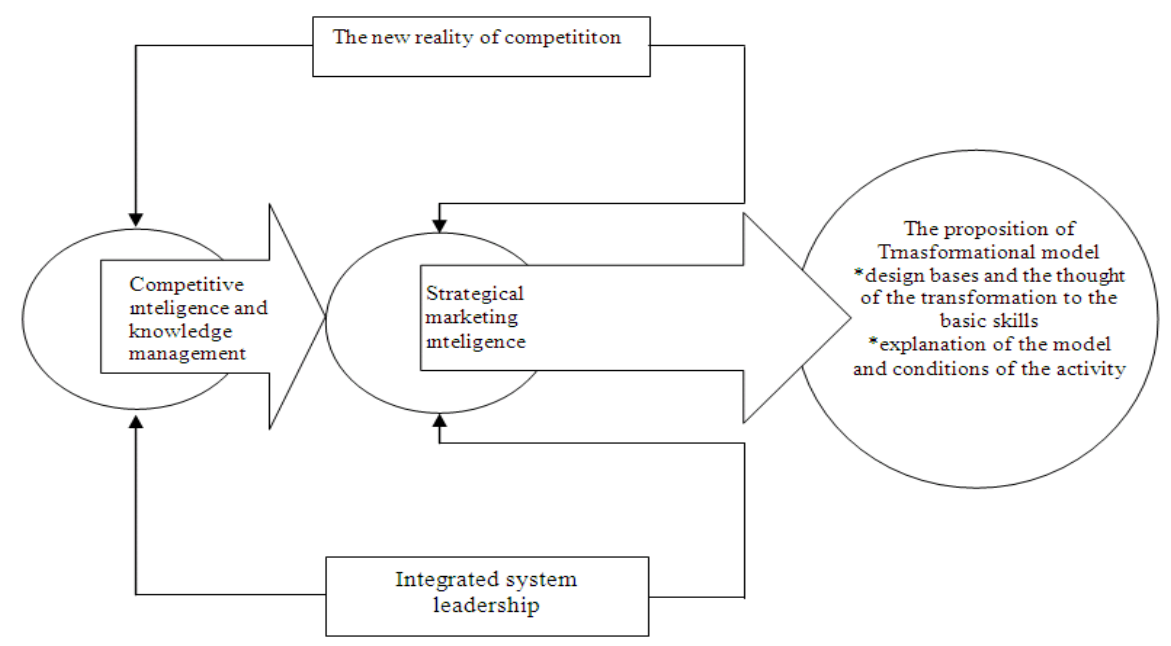

Fig. 1: The genius of the study and its positioning

The New Reality of Competition: Basic Features and Dynamics: In today's dynamic business environment, competition is evolving rapidly to its new reality (Warren, 2002; Barney, 2010; Moore, 1997; Williams, 1992; Peteraf, 1993).

Competition is from now on appears beyond successive moves directed to affecting today's conditions, but is known as a process creates future conditions and covers integrated moves. In this process success is thought as to be able to envisage businesses' market trends, to keep the needs of changing customer needs quickly and by creating new necessities, to transform consumer habits (Moutinho and Southern, 2010; Vella and McGonagle, 2000).

According to such a thought, the essence of competition is not the structure of products and markets of the business but is the dynamic and integrated attitude that the business take. Moreover, if the businesses delimitate themselves to existing competitive environment with an organized consistency, they can reach success in a certain extent, but in competition, the possibility of having a permanent solution is assessed low. Because for a permanent solution in competition, it is necessary for the businesses to develop an effective systematical approach which enables to do their best in changing environment freely, to keep themselves in the same development line together with their markets and customers and up to a certain level, to be able to change the variation systems/processes.

Russel Ackoff describes the system as "a physical or ideational entity which consists of interdependent departments". Or a system can be described as "a whole which cannot be divided into independent departments" (Barabba, 1995; Dodgson and Hughes, 2009). The meaning of this in new reality of competition is, if the business wants to be successful as whole, in the organization, every component should act together with the others within a trust relationship. The best way of solving the problems is not to deal with it functionally, but is to take the problems to a higher system and to solve it under an integrated mechanism. In other words, it is dividing the problems into small pieces and then reunite them towards the defined target/aim. This thought is oriented to be able to comprehend the relationship between the problem and the higher system. Even in advanced thought, it should be the observing the effects of problem solving within "an environmentally interacted integrity". In this process the main understanding, can be crystallized as "system synergy" which was envisaged by Aristo centuries ago. Because it should be thought that, the sub-systems that designed independently, cannot be appropriately useful for the organization. System synergy means higher energy production than aforesaid sub-systems' energy (System Approach; (a) interdisciplinary approach, (b) integrated approach and (c) depends on scientific approaching principles (Laszlo et al., 2010; Zexian and Xuhui, 2010). To qualify the business's system energy," Strategic Marketing Intelligence (SMI) (The concept of intelligence" is handled multidimensional in business literature; even "competitive intelligence is used in place of the concepts of business intelligence and organizational intelligence and each others'. In our study these concepts are given as a comparative quality of each other not as trying to separate one from another and the concept of "strategic marketing intelligence" is handled as an integrating concept)" has been used recently and it is seen as a new expansion for keeping up with competition's new reality/future. 
The Concept of Strategic Marketing Intelligence: In order to comprehend SMI related to the new reality of competition, first of all the contents of competitive intelligence and knowledge management concepts should be investigated thoroughly. Because these are the main arguments that consist the basis of MSI. According to this, in narrow sense, the competitive intelligence is described as "the informatics that provide businesses to be the more effective", however, this definition is not thought enough, the definition made by Business Intelligence Institute in America is assessed as the most adequate one (Trim and Lee, 2008; Trim, 2004; Walle, 1999a; 1999b; Powell and Allgaier, 1998).

According to this definition:

"“"Competitive/Business intelligence is the total knowledge a company possesses about the environment in which it competes. It is synthesized from the vast amount of bits and pieces of external information bombarding the firm every day. It paints a whole picture of the present and future competitive arena of management decisions."

According to a comprehensive definition:

"Competitive intelligence is the art and science of preparing companies for the future by way of a systematic knowledge management process. It is creating knowledge from openly available information by use of a systematic process involving planning, collection, analysis, communication and management, which results in decision-maker action”.

In other words, the competitive intelligence is the process of creating information from clearly obtained informatics by using planning-including a systematic process for deciding actions-collecting, analyzing, communication and management (Calof and Wright, 2008; Dishman and Calof, 2008; Ishikawa, 2001; O'Guin and Ogilvie, 2001; Powell and Dent-Micallef, 1997).

Therefore, the purpose of competitive intelligence is to able to understand the customers, suppliers, rivals or shareholders and moreover to obtain and create new opportunities.

Indeed the main purpose of competitive intelligence is to be able to see the changes may occur in one of these dynamics before and for the business, to determine the best location in order to transform the changes to advantages; but functional actions/integrated processes and during the phase of transforming information to competitive advantage it can be sometimes inadequate (Liu et al., 2010; Lin and Chen, 2008; Viviers and Calof, 2002; Wood, 2000). Leading from all these, MSI assesses the competitive intelligence as a strengthener of the organization by filling the existing gaps from the point of being a cross coordinate and covering an integrating process. The most important point here is the capability of all the working people in the business about comprehending thoroughly the marketing/strategic marketing definition and in this extension they should obtain the thinking skills. These thinking skills qualify three understandings: (Pole et al., 2000) (a) institutionalized agility skills, (b) all working activities' representing the processes (c) the only purpose's being customer pleasure. In other words all the businesses have only one purpose; whatever their sector and quality is-"to obtain permanent customer" Or it can be said like this; to keep existing customers and to gain possible ones and to obtain permanent customer, businesses should crucially assess their strategic marketing intelligence (Woodruff, 1997; Slater and Narver, 2000; Hart et al., 2003). In this sense, as mentioned before SMI's relationship with two important disciplines knowledge management and competitive intelligence is highly significant. Knowledge management is a systematical approach which helps in information/informatics existence and providing the value forming with correct customer at correct time (Linder and Seidenstricker, 2010; Helfat and Raubitschek, 2000; Teece, 1998). Whereas competitive intelligence is collecting, analyzing and managing the external information which can be effective in the organizations increasing market competition, Plans of the organization for systematical and ethical programs. So both disciplines knowledge management and competitive intelligence must be systematical and effective in order to increase competitive values/advantages for the organizations.

The Restructuring of Strategic Marketing Intelligence: Competitive intelligence is the subgroup of knowledge management, which includes external information of the market place and consist all the data of the organization. SMI is a complex and comprehensive structure which provides both structures' integration with each other and coordination. Organizations should act through four important principles to construct SMI with competitive intelligence and knowledge management studies Consortium Benchmarking Study Best-Practice Report (Day and Montgomery, 1999) these are:

- Competitive intelligence must direct to correct customers/people at correct time 
- The organization should be ready to accept envisaged the expert people about competitive intelligence and must have them easily

- Competitive intelligence should be capable of transferring information and the best applications

- For the sake of SMI's formation, the organization should be open to cross-coordinative actions

To obtain competitive intelligence for correct customers/people at correct time: While forming strategies connected to markets, it is leading the best applications of the organization to the people who are in need at correct time when they need competitive intelligence. Here it is the main point is submission of competitive intelligence data as aimed way and donation of all domestic networks of the business to competitive intelligence. Competitive Intelligence's being lead correctly and as the aimed way, it is crucial to form organizational structures simplifying data share. And It requires reconstruction of the organization as in the way of facilitating the data share with cross-work functions.

To give job to the experts of competitive Intelligence: Another important principle in forming SMI is to give job opportunities to the advanced/experienced specialists about competitive intelligence in the organizations, in order to obtain their organized information keys, it is highly needed to form an activity mechanism and its applicability. And for this, it should be thought to activate these processes: (i) to employ the persons who are expert in their own branches by talking personally and with various aimed questions to have intrinsic communication. (ii) to define expert people and clarify their being reachable through intranet. (iii) To comprise competitive intelligence networks. By the help of this we benefit from expert competitive intelligence networks' elevating effect.

To be able to transfer information and the best applications: In forming MSI the third component is the ability to transfer information and the best applications of competitive intelligence. To form such a mechanism the basic necessities are periodical forms, information fairs, guides, discussion groups, e-mail and distribution lists, competitive intelligence teams, the competitive intelligence personnel's internal and external rotation, excellent competitive intelligence centre, competitive intelligence databases and intranets. Competitive intelligence teams head the cross functional teams and every team is responsible for reaching related topics quickly with a special key rival. These teams are responsible for being able to transfer the learned courses related to their specific rival whose informatics is needed.

Organization's being tolerant against cross coordinative activities: In forming SMI, Cross Coordinative Activities cause the excellent ideas are assessed synchronically and normally meaningless information when it is alone, here comes together with the other ones and become meaningful and this is provided by cross coordinative activities. Just like the loops of a carpet, how they are meaningless alone and when they come together they form the carpet and have a great value; this is just in the case of Cross Coordinative Activities. If the organization is tolerant to Cross Coordinative Activities, it will ease the development of marketing understanding and the organization won't be dependent or limited to the obtained information and market informatics, by this way the business will envisage what can be done as a whole.

The proposition of strategic marketing intelligence model: SMI transformational model proposition has been assessed related to settling the telescoping system which is connected to the new reality of competition and integrated system leadership and helpful at determining their own system development and at easing the obtainment of the system leadership by presenting a reliable topographic map. In this model, first of all explaining the basic thought of the design and later transforming this thought to the core competence of business have great importance.

The design bases of model and the idea of transforming core competence: In general sense, for the model design and the idea of developing, the preparation notes are assessed from the angle of (a) design bases (b) the idea of transforming core competence.

Model design bases: In the design of SMI model proposition, there is a trivet including (i) forming a common marketing language/operable model among the organization (ii) transforming internal complexity to causal ambiguity (iii) perception of external uncertainty as opportunities (Fig. 2).

Forming a common marketing language/operable model among the organization: In order to form the system and for gaining functionality of SMI, it is adhere to the condition if a development cannot be obtained in forming an operable model and if a general fault is done in differentiating the marketing concept and the market itself. 


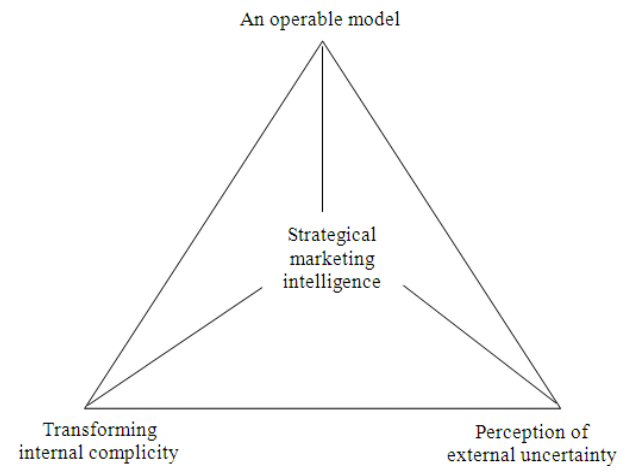

Fig. 2: The trivet of strategic marketing intelligence

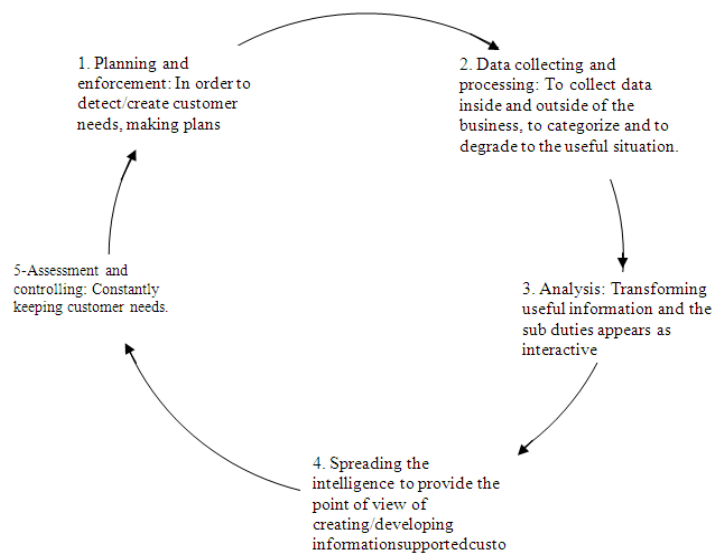

Fig. 3: The cycle of transforming SMI to core competences Source: Viviers and Calof (2002)

If the complexity is taken into account which is surrounding market/marketing terms, not forming a frame that rendering marketing concept functional is not so surprising. The arguments about marketing and not realized compromises are hindering the comprising of a common understanding. However, "marketing" controls interpersonal network which bridge over among all living people and the other people who are not able to appear in any of the functional department of the business; moreover the statement " marketing is a competitive defiance " can be effective in forming a common marketing language/operable model.

Transforming internal complexity to causal ambiguity: Another important trivet in forming the system is transforming internal complexity to causal ambiguity. Complexity consists of lots of elements that compose a topic or a problem and the interaction of these elements with each other. When this elements and interactions are mixed, a difficulty arises in analysis and decision phase. When looked from that side, business's awareness against complexity problem and without neglecting it, the effort of trying to comprehend, are all handled as presuppositions in creating causal ambiguity. From the point of view, complexity is a part of continuity of the work, decision, serving to the customers and effective informatics, it is essential to find a way of to cope with it. For this struggle a double way process can be developed: (1) To collect and comprehend customer values as a shared vision among the business and all the personnel (2) to form vision that will detect the most effective way to keep these customer values (Reed and DeFillippi, 1990).

Perception of external uncertainty as opportunities: The last trivet in the system forming is the perception of external uncertainty as opportunities. In every market the existence of reason and harmony in itself causes every customer/ rival's creating a cycle in the market pool and later on each is dragged in market's own flow. So that, the more powerful business marketing tools are, the less they sweep over in this current.

The idea of transforming core competence: About the topic of creating superior values to the customers/organization SMI includes business intelligence and all the organizational intelligence process and can be highly effective in correct leading/accelerating competitive analysis and decision process. However a difficult and a hard process is the obtainment and internalizing of SMI in a business, once it is obtained/developed and constantly provided, it can be turn into a competence which is hard/costly to be copied by the rivals of the business (Draganidis and Mentzas, 2006; Collis and Montgomery, 1995).

In the process of formation and development process of SMI of the business lots of steps are in subject: These steps define SMI functions (Christensen and Overdorf, 2000).

The steps appears in the cycle/ideal display of transforming SMI to core competence are shaped as; (i) Planning and enforcement, (ii) data collecting and processing, (iii) analysis, (iv) Spreading the intelligence, (v) Assessment and controlling (Viviers and Calof, 2002; Wood, 2000: 283-299; Desouza, 2001) (Fig. 3).

Planning and enforcement: The organization should be aware of the complexity and uncertainty. It is not possible to have loose ideas about the issues of the answers that to be given to the customers or rivals' activities. It is necessary to develop and enforce a plan that will determine, change, create and transform the customer needs. 
Am. J. of Economics and Business Administration 3 (3): 479-489 2011

Table 1: The explanation of the perspectives for transformational model proposition

\begin{tabular}{|c|c|}
\hline Perspective & Explanation \\
\hline High performance perspective & $\begin{array}{l}\text { This perspective helps to summarize the works done in the past and about these events and the actual } \\
\text { situation's measurable economical results and reveals whether the business basic strategy and the enforcements } \\
\text { and applications that related to the strategy contributed to the development of the business or not.. }\end{array}$ \\
\hline Customer perspective & $\begin{array}{l}\text { This perspective, defines the customer that the business will compete, market departments and in these target } \\
\text { departments, the measurements of the success that the business shows. This perspective, includes the measures } \\
\text { of satisfaction, conservation of the customer, gaining new customers, customer profitability and market } \\
\text { /customer shares in the target places. Thus, the values are determined that will be presented to the customers } \\
\text { who are at the business' aimed market department }\end{array}$ \\
\hline $\begin{array}{l}\text { Internal perspective } \\
\text { and learning }\end{array}$ & $\begin{array}{l}\text { This perspective, is related to the important internal processes have to be developed and brought into perfection } \\
\text { by the business. By this way, business' presenting values that will ease to attract and conserve the customers in } \\
\text { the aimed market places, keeping sharers' high profit expectations and learning chances are investigated The } \\
\text { measurements places in the processes customer satisfaction and the business focuses on internal process } \\
\text { methods which are the most effective ones on the way of reaching financial targets. The value chain of the } \\
\text { internal processes is consisted by the activities in the process from the completion of customer necessities to } \\
\text { keeping customer necessities. While forming design and development innovation process, production, marketing, } \\
\text { and post sale services form operations process. In this process the success redound on financial success. }\end{array}$ \\
\hline Expansion perspective & $\begin{array}{l}\text { Expansion perspective is related to the needed infrastructure for long term growth and development in the } \\
\text { business. Customer and internal perspective targets determine the factors would be necessary in the future. There } \\
\text { is a gap between the state that the business in and the state that should be reached. In order to make up the } \\
\text { difference, businesses must have their workers and institutions gain new skills, improve the informatics } \\
\text { technology and systems and be harmonically working with business processes and programs. The measures that } \\
\text { take business workers as base are personnel satisfaction, education and abilities; in addition to these, more } \\
\text { detailed and specific measures are also important such as; special abilities that prepares a new competitive } \\
\text { environment and signs that reflects to business' commercial activities. }\end{array}$ \\
\hline
\end{tabular}
Source: Kaplan and Norton (1999); Kaplan and Norton (1996a)

Data collecting and processing: It is necessary to collect business internal and external data, to categorize them and by degrading to the minimum level, it is necessary to be gained functionality. The market information that obtained during the process provides constant service/product which are in balance with business capacity and resources and it is innovative and containing customer pleasure.

Analysis: The analysis step of this cycle includes the formation of own sub-duties which are in necessity of management in order to form effective inputs and outputs. But this is only possible with a good analysis skill. In developing SMI analysis studies are in interaction with all sub-processes.

Spreading the intelligence: It is necessary to have a sense of direction in all the organization members which helps them about producing certain product/service that creates customer pleasure/value. The purpose of the organization shouldn't be reminded to anybody.

Assessment and controlling: This step is necessary especially in collecting process of required feedback and assessment after evaluating the customers' existing/continuous and possible necessities and to restructure them. In this step, there is an authorization in the general of the organization. Direction is apparent; the resources that will keep the targets are determined with innovating decisions, responsibilities are well defined and the way which the application will follow is clearly detected. The management of the units from the top is beside the point.

The explanation of transformational model proposition: In this framework, business transformational model proposition can be developed under the basis of four simple perspectives: (This thought, is assessed related to the thought of "balanced score card" and its components which are started with Robert S. Kaplan's and David Norton's head called as "Performance measurement in future organizations "in 1990. Kaplan and Norton $(2004 ; 1999 ; 1992 ; 1996 b)$ these are (a) High performance perspective, (b) customer perspective (c) Internal perspective and learning (d) Expansion perspective (Table 1).

While high performance perspective is defining concrete results of SMI with traditional performance expressions, customer perspective is defining value presentation for the target customers. High performance perspective and customer perspective define the expected result from SMI. Whereas internal perspective detects some of critical processes which are expected to be the most effective to SMI. Expansion and learning perspective is detecting non-physical resources which are important for SMI. In this perspective aims are determining which works and systems, what kind of an environment are necessary to support internal processes creating value. In this perspective resources are integrated and by this way they are provided as harmonious with critical internal processes (Choo, 2001) (Fig. 4). 
Am. J. of Economics and Business Administration 3 (3): 479-489 2011

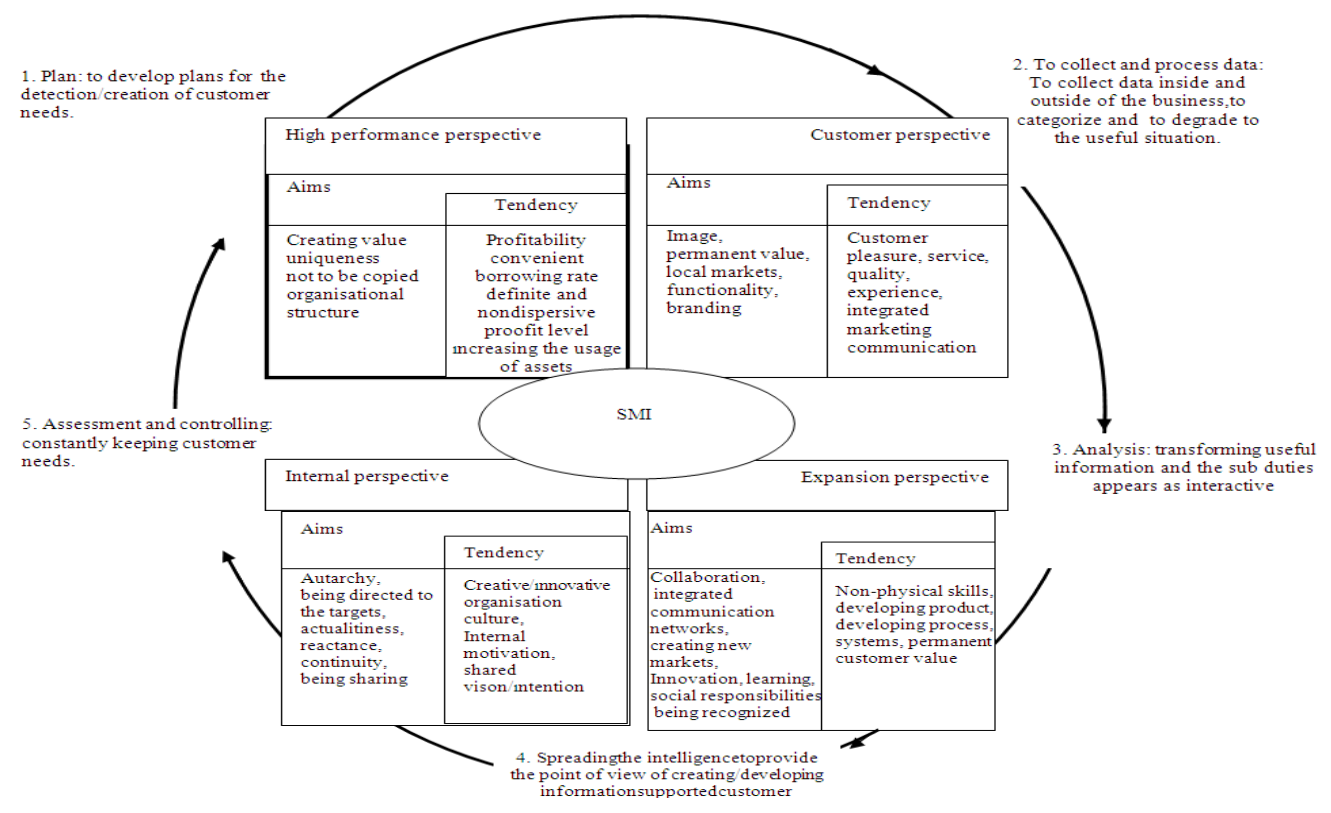

Fig. 4: SMI transformational model: The targets in four basic fields and performance

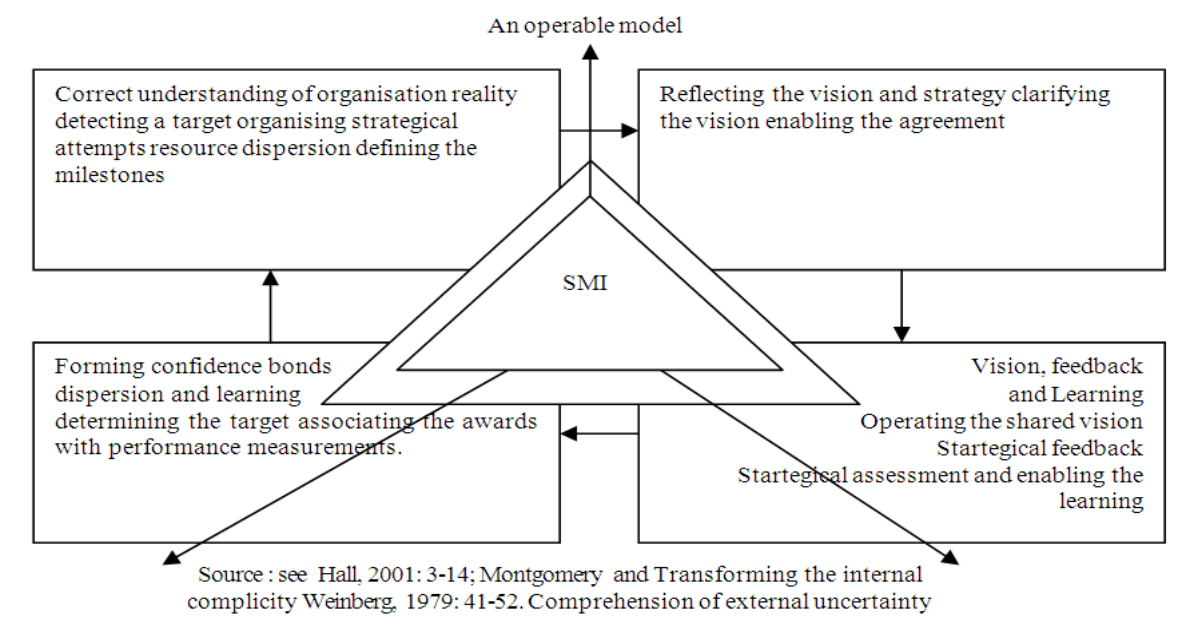

Fig. 5: SMI proposition model activity conditions and interactions

The reason-result architecture, which connects these four perspectives appear in business transformational model, is the basic structure of SMI formation. The formation of SMI is also important from the side of the business, clarification of for whom it will produce permanent value. At this point, activity conditions can be assessed as like this (Fig. 5).

Correct understanding of organization reality: Understanding the organization reality correctly has a great importance from the point of integrating the wished plans and attempts with strategically targets and corrects assessment of the results. Directed to this resource allocation has an importance when they satisfy superb management targets, dependent to detecting the priorities, dependent to reason result relationship, providing the coordination of movements that are strategically target-oriented.

Reflecting vision and strategy: sharing the vision expresses the unity in the understanding. Transforming the strategies to the action redound on the way of leading, being targeted or realization. Agreement provides power and success. However, oriented to this, 
organizational ability, work processes, customer value and other profits should be taken into account.

Forming confidence bonds: It is necessary to form trust/confidence bonds and convey it to all levels and they should be reflected to personal/organizational purposes. By this way both the understanding of the strategies is provided and personal/organizational purposes are oriented to this.

Feedback and learning: For every business the important thing is learning. Every feedback facilitates the focusing, oriented to the business purposes. In qualifying this process, transforming strategies to actions has a great importance, too.

Together with this, business transformational model is a coordinative tool which provides cooperative work among SMI workers of business, other workers and organization members in marketing culvert. Here the important thing is to be able to develop new approaches which can find multiple solutions to marketing problems and to assure the state that subjects possible plans to business continuity. The model that indicated and already existing in Fig. 4 and its certain components have appreciable importance and they can appear in the organizational structure. Indeed, the interested thing is market powers and the effects of external powers on the organization, because of this reason, as Porter indicated in his studies among the years $1980-85$, it is necessary for the organization to answer to the competitive situations and to retaliate (Porter, 1980). In the meantime, in order to be effective in competition, business must well define SMI and intelligence personnel should exceed the organizational handicaps meticulously which can hinder the organizational mobility of informatics (Davison, 2001).

Inadequate informatics mobility can cause these problems stated below in an organization (Trim, 2004):

- Duplication of informatics sources

- Decomposition of informatics

- Informatics' being not assessed within the system

- Delay in decision when the different opportunities are came across which is oriented to available of informatics

- Incompletion of the plans as a result of inadequate informatics synergy

In such occasions, it can be necessary to change the structure of the organization and if it is possible, it is necessary to redefine and recreate the organization culture. From this side, senior workers of the organization must devote themselves to the process of change and must share their vision with other workers (Prescott et al., 1998; O’Gorman, 2005).

Conclusion and assessment: Today's market/competition dynamics' has important effects on business basic and other functions causes the increasing importance of SMI. Especially the increment/enhancement of inter-organization network structures, marketing culverts, marketing activities over internet, augments the requirement of dependable inter-organizational information sharing and sets forth the obligation of assessment of the personnel's' working with the workers inside/outside of the organization in a coordinative and integrated structure.

Concordantly, businesses are in need of the transformational in order to bring together their market/customer oriented values and resources in full time; at the same time to present analyzing approaches to the emerged problems, for the purpose of effecting/formalizing the future. As a matter of fact, the transformational model proposition provides advantage to the businesses in forming and developing SMI in these ways below:

First of all it gives highly important strategic equipment to the businesses about the issues of examining the competitive environment better and making use of opportunities and creating new opportunities, envisaging the threads and eliminating them and evolving together. Later, it lets the business gain a totally adopted and internalized quality by shifting the dominant functions, management/financial ideational structure to the axis of marketing /competition. Because the inspiration source of this model is the motto of "the best way to envisage the future is to invent it", it expresses the current soul of SMI.

\section{MATERIALS AND METHODS}

This study is handled as a qualitative assessment related to restresssing content of the concepts and to theorize an explanatory hypothesis under the base of data and document analysis. Now therefore, it's evaluated as a conceptual study connected to theorizing model. Therefore, a model is proposed. This model is assessed related to the thought of "balanced score card" and its components which are started with Robert S. Kaplan's and David Norton's head called as "Performance measurement in future organizations "in 1990.

The aim this model is to give the vision of creating loops and functional/behavioral road map. 


\section{RESULTS}

SMI transformational model proposition has been assessed related to settling the telescoping system which is connected to the new reality of competition and integrated system leadership and helpful at determining their own system development and at easing the obtainment of the system leadership by presenting a reliable topographic map.

In this framework, business transformational model proposition has been developed under the basis of four simple perspectives: These are (a) High performance perspective, (b) customer perspective (c) Internal perspective and learning (d) Expansion perspective.

The reason-result architecture, which connects these four perspectives appear in business transformational model, is the basic structure of SMI formation.

At this point, activity conditions have been assessed as four this (Fig. 5).

\section{DISCUSSION}

Sustainable competition, qualifies a process that comprise (includes) holistic actions which creates management's future conditions/states. This process requires management to change transformation systems or developing systematical approaches that contains more efficient and interactive unity of environmental for future. Here positioned intertwined systems, provides uninterrupted flow of energy to the system. In contrast disruption of energy breaks off interactive unity of environmental from its context and damage sustainability.

In that respect, first, reasons of sustainability competition is investigated and then theoreticalconceptual or intellectual modeling orientated to provide it, is tried to make in the study. This model is associated with balanced score cards components that are shaped by Kaplan\&Norton; then performance perspective is developed originally in terms of both approach and configuration on the need of primarily supporting the processes that create value,

In the model, it is adopted that the effect of environmental dynamics reveals when conditions of implementation exist, however, the match of conditions of implementation and environmental dynamics is always assumed to be possible. Therefore it has been thought that this assumes support/contributes in the way of creating model implementation opportunities of dynamic environment all the time and in each case.

In general context, it may be argued that this study is prove for management and supports multi-directional views and findings about the literature. Besides, it is expected that management transform internal complexity for an operable process, due to the pressure of the fact that today's dynamic and competitive business environment. Therefore, model that is developed and proposed should be evaluated regarding to affect of thoughts of transforming core competence and perception of external uncertainty.

In the content of study, Strategic Marketing intelligence is emphasized as a driver of competitive intelligence and information management in terms of new reality of competition and, it has been expressed that transformational model was an expected result. In this context, first of all the study contribute intellectually to the literature in terms of holistic system leadership by supporting management's intermediate-model implementations and it can be argued that the study has an encouraging feature for further implementations and studies. Also, as guiding characteristic of the study will bring the idea of gradual realization of necessary transformation, it may point the development and structuring of the ideas on the model.

Definitely, conceptual and theoretical direction of the study includes a natural limitation. However, that can be said it provided a useful way with, implementation quality of the model, management's participation to model and intermediate-models that they will develop and/or believes and performances of the implementers to achieve this.

\section{CONCLUSION}

To conclude, a business's existing in today/future, not being a follower but to be the followed one, always without losing setting sail in a free soul, handling integral system leadership are all depend on creating permanent values/being in action oriented activities. Creating permanent values/being in action oriented activities can be possible just with correct assessed/lead informatics, inclusive/completive SMI, which is reachable, correct, full in time, cross coordinative, shared.

As a matter of fact, the transformational model proposition provides advantage to the businesses in forming and developing SMI in these ways below:

First of all it gives highly important strategic equipment to the businesses about the issues of examining the competitive environment better and making use of opportunities and creating new opportunities, envisaging the threads and eliminating them and evolving together. Later, it lets the business gain a totally adopted and internalized quality by shifting the dominant functions, management/financial 
Am. J. of Economics and Business Administration 3 (3): 479-489 2011

ideational structure to the axis of marketing/competition. Because the inspiration source of this model is the motto of "the best way to envisage the future is to invent It.", it expresses the current soul of SMI.

\section{REFERENCES}

Barabba, V.P., 1995. Meeting of the Minds: Creating the Market-Based Enterprise. 1st Edn., Harvard Business School Press, Boston, MA., ISBN-10: 0875845770, pp: 247.

Barney, J., 2010. Gaining and Sustaining Competitive Advantage. 4th Edn., Pearson Education Canada, ISBN: 013612092X, pp: 592.

Viviers, W. and J.L. Calof, 2002. International information seeking behavior of South African exporters. South African J. Inform. Manage., 4: 1-11.

Calof, J.L. and S. Wright, 2008. Competitive intelligence: A practitioner, academic and interdisciplinary perspective. Eur. J. Market., 42: 717730.

Choo, C.W., 2001. Environmental scanning as information seeking and organizational learning. Inform. Res., 7: 1-25.

Christensen, C.M. and M. Overdorf, 2000. Meeting the challenge of disruptive change. Harvard Bus. Rev., 78: 66-77.

Collis, D.J. and C.A. Montgomery, 1995. Competing on resources: Strategy in the 1990s. Harvard Bus. Rev., 73: 118-129.

Davison, L., 2001. Measuring competitive intelligence effectiveness: insights from the advertising industry. Competitive Intell. Rev., 12: 25-38. DOI: 10.1002/cir.1029

Day, G.S. and D.B. Montgomery, 1999. Charting new directions for marketing. J. Market., 63: 3-13.

Desouza, K.C., 2001. Intelligent agents for competitive intelligence: survey of applications. Competitive Intell. Rev., 12: 57-63. DOI: 10.1002/cir.1032

Dishman, P.L. and J.L. Calof, 2008. Competitive intelligence: A multiphasic precedent to marketing strategy. Eur. J. Market., 42: 766-85. DOI: 10.1108/03090560810877141

Dodgson, M. and A. Hughes, 2009. Systems thinking, market failure and the development of innovation policy: The case of Australia. Centre for Business Research, University of Cambri dge, Working Paper No. 397.

Draganidis, F. and G. Mentzas, 2006. Competency based management: A review of systems and approaches. Inform. Manage. Comput. Secur., 14: 51-64. DOI: 10.1108/09685220610648373
Hart, S.L., M.B. Milstein and J. Caggiano, 2003. Creating sustainable value. Acad. Manage. Executive, 17: 56-69.

Helfat, C.E. and R.S. Raubitschek, 2000. Product sequencing: Co-evolution of knowledge, capabilities and products. Strategic Manage. J., 21: 961-979.

Ishikawa, K., 2001. The Japanese Intelligence Culture. Competitive Intell. Rev., 12: 51-56. DOI: 10.1002/cir.1031

Kaplan, R.S. and D.P. Norton, 1999. Balanced Scorecard-Measures that Drive Performance. Harvard Business Review.

Kaplan, R.S. and D.P. Norton, 1992. The balanced scorecard: Measures that drive performance. Harvard Bus. Rev., 71-79.

Kaplan, R.S. and D.P. Norton, 1996a. Linking the balanced scorecard to strategy. California Manage. Rev., 39: 53-79.

Kaplan, R.S. and D.P. Norton, 1996b. Using the balanced scorecard as a strategic management system. Harvard Bus. Rev., 74: 75-87.

Kaplan, R.S. and D.P. Norton, 2004. Strategy Maps: Converting Intangible Assets into Tangible Outcomes. 1st Edn., Harvard Business Press, Boston, Mass., ISBN: 1591391342, pp: 454.

Laszlo, A., K.C. Laszlo and H. Dunsky, 2010. Redefining success: designing systemic sustainable strategies. Syst. Res. Behav. Sci., 27: 3-21. DOI: 10.1002/sres.982

Lin, M.J.J. and C.J. Chen, 2008. Integration and knowledge sharing: Transforming to long-term competitive advantage. Int. J. Organ. Anal., 16: 83108. DOI: 10.1108/19348830810915514

Linder, C. and S. Seidenstricker, 2010. The strategic meaning of ingredient brands: A resource-based analysis. Asian J. Market., 4: 1-16. DOI: 10.3923/ajm.2010.1.16

Liu, L., V. Timothy and Y. Gao, 2010. A review of approaches of resource-based empirical research in banking. Int. J. Applied Econ. Finance, 4: 230-241.

Moore, J.F., 1997. The Death of Competition: Leadership and Strategy in the Age of Business Ecosystems. 1st Edn., Harper Paperbacks, USA., ISBN-10: 0887308503, pp: 320.

Moutinho, L. and G. Southern, 2010. Strategic Marketing Management: A Business Process Approach. 1st Edn., Cengage Learning, Hampshire, UK., ISBN: 1844800008, pp: 490.

O'Gorman, D., 2005. Memes, CI and marketing: A preliminary framework. J. Competitive Intell. Manage., 3: 29-43.

O'Guin, M.C. and T. Ogilvie, 2001. The Science, Not Art, of Business Intelligence. Competitive Intell. Rev., 12: 15-24. DOI: 10.1002/cir.1028 
Peteraf, M.A., 1993. The cornerstones of competitive advantage: A resource-based view. Strategic Manage. J., 14: 179-191.

Pole, J.G., M. Erik and P. Dishman, 2000. Competitive intelligence as a construct for organizational change. Competitive Intell. Rev., 11: 25-31. DOI: 10.1002/1520-6386(200034)11:4<25::AIDCIR5>3.0.CO;2-U

Porter, M.E., 1980. Competitive Strategy: Techniques for Analyzing Industries and Competitors. 1st Edn., Park Avenue, SL., pp: 396.

Powell, T. and C. Allgaier, 1998. Enhancing sales and marketing effectiveness through competitive Intelligence. Competitive Intell. Rev., 9: 29-41. DOI: $10.1002 /($ SICI $) 1520-$ 6386(199810/12)9:4<29::AID-CIR6>3.0.CO;2-0

Powell, T.C. and A. Dent-Micallef, 1997. Information technology as competitive advantage: The role of human, business, and technology resources. Strategic Manage. J., 18: 375-405.

Prescott, J., J. Herring and P. Panfely, 1998. Leveraging information for action: a look into the competitive and business intelligence consortium benchmarking study. Competitive Intell. Rev., 9: 4-12.

Reed, R. and R.J. DeFillippi, 1990. Causal ambiguity, barriers to imitation, and sustainable competitive advantage. Acad. Manage. Rev., 15: 88-102.

Slater, S.F. and J.C. Narver, 2000. Intelligence generation and superior customer value. J. Acad. Market. Sci., 28: 120-127. DOI: 10.1177/0092070300281011

Teece, D.J., 1998. Capturing value from knowledge assets: The new economy, markets for know-how, and intangible assets. California Manage. Rev., 40: 55-79.

Trim, P.R..J., 2004. The strategic corporate intelligence and transformational marketing model. Market. Intell. Plann., 22: 240-256. DOI: $10.1108 / 02634500410525896$
Trim, P.R.J. and Y.I. Lee, 2008. A strategic marketing intelligence and multi-organisational resilience framework. Eur. J. Market., 42: 731-745. DOI: 10.1108/03090560810877123

Vella, C.M. and J.J. McGonagle, 2000. Profiling in competitive analysis. Competitive Intell. Rev., 11: 20-30. DOI: 10.1002/(SICI)15206386(200032)11:2<20::AID-CIR5>3.0.CO;2-G

Walle, A.H., 1999a. From marketing research to competitive intelligence: Useful generalization or loss of Focus? Manage. Decision, 37: 519-525. DOI: 10.1108/00251749910278041

Walle, A.H., 1999b. Corporate configurations and competitive intelligence: Understanding organizations at a distance. Competitive Intell. Rev., 10: 55-64. DOI: 10.1002/(SICI)15206386(199934)10:4<55::AID-CIR8>3.0.CO;2-V

Warren, K., 2002. Competitive Strategy Dynamics. 1st Edn., John Wiley and Sons, Inc. New York, ISBN: 0471899496, pp: 330.

Williams, J.R., 1992. How sustainable is your competitive advantage? California Manage. Rev., 34: 29-51.

Wood, E., 2000. Marketing information systems in tourism and hospitality small- and medium-sized enterprises: A study of Internet use for market intelligence. Int. J. Tourism Res., 3: 283-299. DOI: $10.1002 /$ jtr.315

Woodruff, R.B., 1997. Customer value: the next source for competitive advantage. J. Acad. Market. Sci., 25: 139-153. DOI: 10.1007/BF02894350

Zexian, Y. and Y. Xuhui, 2010. A revolution in the field of systems thinking-a review of Checkland's system thinking, Syst. Res. Behav. Sci., 27: 140-155. DOI: $10.1002 /$ sres. 1021 